\title{
DESIGN, DEVELOPMENT, AND CHARACTERIZATION OF OCIMUM BASILICUM MUCILAGE-BASED, MODIFIED RELEASE MUCOADHESIVE GASTROSPHERES OF CARVEDILOL
}

\author{
SAKHARE SS ${ }^{1,2 *}$, SAYYAD FJ ${ }^{2}$ \\ ${ }^{1}$ Department of Pharmaceutics, Gourishankar Institute of Pharmaceutical Education and Research, Limb Satara, Maharashtra, India. \\ ${ }^{2}$ Department of Pharmaceutics, Government College of Pharmacy, Karad, Maharashtra, India. Email: sfurti_28@rediffmail.com
}

Received: 09 July 2019, Revised and Accepted: 30 July 2019

\section{ABSTRACT}

Objective: The present investigations aim to develop mucoadhesive gastrospheres of carvedilol using sodium alginate and Ocimum basilicum seed mucilage combination blend oral use.

Methods: The gastrospheres were prepared by ionotropic gelation method using $3^{2}$ factorial designs, the concentration of sodium alginate and $O$. basilicum mucilage was independent variables while \% drug content (DC), \% entrapment efficiency, and \% drug release at $12 \mathrm{~h}$ were dependent variables. The gastrospheres were evaluated for other parameters such as Fourier-transform infrared (FTIR), powder X-ray diffraction, differential scanning calorimetric, and in vitro mucoadhesion studies.

Results: In optimization studies from statistical second-order complete model equation among the polymers used 0 . basilicum mucilage had a more profound effect on DC and \% encapsulation efficiency as compared to sodium alginate. The mean particle size of gastrospheres when measured by optical microscopy technique ranged from 774 to $882 \mu \mathrm{m}$. The percentage of gastrosphere adhering to goat intestinal mucosal tissue varied from $10 \%$ to $65 \%$ over $8 \mathrm{~h}$ in $0.1 \mathrm{~N} \mathrm{HCl}$, whereas this was varied from $40 \%$ to $60 \%$ in phosphate buffer $\mathrm{pH} 6.8$ with provided $12 \mathrm{~h}$ of controlled release following zero-order release pattern.

Conclusion: Studies conclude that mucilage of $O$. basilicum can be used as controlled release mucoadhesive material in the formulation of gastrospheres.

Keywords: Gastrospheres, Mucoadhesion, Ocimum basilicum.

(c) 2019 The Authors. Published by Innovare Academic Sciences Pvt Ltd. This is an open access article under the CC BY license (http://creativecommons. org/licenses/by/4. 0/) DOI: http://dx.doi.org/10.22159/ajpcr.2019.v12i10.34291

\section{INTRODUCTION}

Drug delivery systems (DDS) that can precisely control the release rates or target drugs to a specific body site have an enormous impact on the health-care system. Carrier technology offers an intelligent approach for drug delivery by coupling the drug to a carrier particle such as microsphere and nanoparticles, which modulates the release and absorption characteristics of the drug. Microsphere/microparticles constitute an important part of this particulate DDS by virtue of their small size and efficient carrier characteristics. These delivery systems offer numerous advantages compared to conventional dosage forms, which include improved efficacy, reduced toxicity, improved patient compliance, and convenience $[1,2]$.

A controlled drug delivery system can overcome some of the problems of conventional therapy and enhance the therapeutic efficacy of a given drug. To obtain maximum therapeutic efficacy, it becomes necessary to deliver the agent to the target tissue in the optimum amount in the right period of time thereby causing little toxicity and minimal side effects. There are various approaches in delivering a therapeutic substance to the target site in a sustained controlled release fashion. One such approach is using microparticles as carriers for drugs. Microparticles can be described as small particles (in 1-1000 $\mu \mathrm{m}$ size range) for use as carriers of drugs and other therapeutic agents consisting of proteins or synthetic polymers which are biodegradable in nature $[3,4]$.

Gastrospheres are the particulate DDSs which achieve the target of gastric retention by mainly two mechanisms, i.e., buoyancy and bio-adhesion. Due to their small size and efficient carrier characteristics, gastrospheres constitute an important part through the particulate novel DDS. The limitation of gastrospheres is due to their short residence time on the site of absorption, and it can be overcome by providing an intimate contact of the drug-delivery system with the absorbing membrane. This can be accomplished by coupling bio-adhesion characteristics to gastrospheres and developing mucoadhesive gastrospheres [5,6]. Extending the residence time with a dosage form at a particular site and controlling the release of drug from the dosage form are useful, especially for achieving controlled plasma level of the drug as well as improving bioavailability.

Mucoadhesive DDSs are the systems which utilize the property of mucoadhesion of certain polymers, which become adhesive on hydration and hence can be used for targeting a drug to a particular region of the body for an extended period of time. Bioadhesion is an integral phenomenon in which two materials, at least one of which is biological are held together by means of interfacial forces. In the case of polymer attached to mucin layer of a mucosal tissue, the term mucoadhesion is used. The mucosal layer lines a number of regions of the body including the nose, Gastrointestinal tract (GIT), urogenital tract, the airways, the ear and eye. Residence time for most mucosal routes is less than an hour, and typically in minutes, it can be increased by the addition of an adhesive agent in the delivery system which is useful to localize the delivery system and increases the contact time at the site of absorption. The exact mechanism of mucoadhesion is not known between the mucoadhesive polymer and mucin occurs, which is followed by the interpenetration of polymer and mucin [7].

Mucilages and gums obtained from natural sources are most widely used as pharmaceutical excipients for their different properties such as its binding, diluents, and disintegrant properties in tablets, suspending, gelling properties in gel, and thickening properties in oral liquids [8-10]. 
Mucilages are also used for their binding, thickening, stabilizing, humidifying, disintegrating, and release controlling properties in medicines [10,11].

Herbal products appear to be more preferred over synthetic ones due to their accessibility, biocompatibility, low cost and low toxicity potential. Mucilage's and gums obtained from natural sources are most widely used as pharmaceutical excipients due to their binding, diluents and disintegrant properties in tablets, due to suspending and gelling properties in gels and due to thickening properties in oral liquids [8-10]. Ocimum basilicum plant has been used in traditional medicine due to its medicinal properties such as antibacterial, antifungal, antispasmodic, carminative, diaphoretic, digestive, emmenagogue, expectorant, stimulant, and stomachic. The plant is generally used in treatments of problems concerning digestion and nervous system. $O$. basilicum gum has been used as an emulsifier [12]. Furthermore, it has been reported that $O$. basilicum seed gum is used as a raw material for the preparation of edible films and coatings [13].

Carvedilol (CRV) is a non-selective $ß$-adrenergic blocking agent with a1blocking activity. It is well absorbed from the GIT but subjected to firstpass metabolism, and its human oral bioavailability is only $20 \%$. For enhancement of CRVs absorption it has been formulated with a series of polymers from point of view of preventing its oral degradation. Since the drug has less solubility and dissolution rate, several methods are used to improve its dissolution rate such as solid dispersions, cyclodextrin complexes, and microcapsules [14]. CRV has short biological halflife of $2 \mathrm{~h}$. Its main absorption site is proximal small intestine [15]. Therefore, it would be lucrative to develop mucoadhesive system of CRV using sodium alginate $-O$. basilicum seed mucilage (OBM) polymer blend for oral use, which might facilitate an intimate contact with the absorbing surfaces of mucous membrane, mucoadhesion and thus the gastric residence could be prolonged to release the drug at target site at controlled rate to maximize the therapeutic effect.

A $3^{2}$ factorial design based computer-aided optimization was employed to investigate the effects of two independent process variables, i.e., amount of OBM and sodium alginate on measured responses such as \% drug content (DC), \% drug entrapment efficiency (DEE), and \% drug released. Therefore, the objectives of the present investigation were to prepare OBM-alginate mucoadhesive gastrospheres containing $\mathrm{CRV}$ and to optimize drug delivery using $3^{2}$ factorial designs.

\section{MATERIALS AND METHODS}

\section{Materials}

CRV was provided ex gratis by Alembic Pvt. Ltd., (Vadodara), sodium alginate (Research Lab. Pvt. Ltd. Mumbai), and calcium chloride $\left(\mathrm{CaCl}_{2}\right)$ (Research Lab. Pvt. Ltd. Mumbai). The O. basilicum seeds were procured from Green Pharmacy, Pune. All other chemicals employed were of analytical grade.

\section{Isolation and purification of $\boldsymbol{O}$. basilicum mucilage}

0 . basilicum seeds were procured and cleaned by washing with distilled water and then soaked in $500 \mathrm{ml}$ of distilled water with intermittent stirring for 12-14 h until soft. The soft seed material was subjected to slow stirring using overhead stirrer (Remi India), and seedless whitecolored mucilaginous material was collected by filtering through muslin cloth. The mucilage was collected and purified by precipitation method by using $250 \mathrm{ml}$ of $95 \%$ ethanol. Collected mucilage was dried in the oven at $50-55^{\circ}$ for $4-5 \mathrm{~h}$. Dried mucilage was scraped with spatula and powdered using mortar and pestle. Mucilage was sieved using mesh no.60 and stored in desiccators for further studies [16].

\section{Preparation of OBM-alginate gastrospheres containing CRV}

The OBM-alginate gastrospheres containing CRV were prepared u1ing $\mathrm{CaCl}_{2}$ as a cross-linking agent by ionotropic gelation method. Briefly, sodium alginate and OBM aqueous dispersions were prepared separately using distilled water. These dispersions were well mixed at 1000 rpm using magnetic stirrer (Remi Motors, India). Afterward, CRV was added to the mixture solutions of sodium alginate and $O$. basilicum mucilage for each formulation and mixed thoroughly using a magnetic stirrer. The final sodium alginate - $O$. basilicum mucilage mixture solutions containing CRV was ultra-sonicated for $5 \mathrm{~min}$ for debubbling. The resulting dispersion was then added through a 21-gauge needle dropwise into $40 \mathrm{ml}$ of $10 \%(\mathrm{w} / \mathrm{v}) \mathrm{CaCl}_{2}$ solutions. Added droplets were retained in the $\mathrm{CaCl}_{2}$ solutions for $15 \mathrm{~min}$ to complete the curing reaction and to produce spherical rigid gastrospheres. The gastrospheres were collected by decantation and washed repeatedly with distilled water and dried at $37^{\circ} \mathrm{C}$ for overnight. The dried gastrospheres were stored in a desiccator until used [6].

\section{Experimental design for optimization}

To obtain "optimized product," nine different formulations were generated using $3^{2}$ factorial designs. The amount of sodium alginate $\left(\mathrm{X}_{1}\right)$ and amount of $O$. basilicum mucilage $\left(\mathrm{X}_{2}\right)$ were taken as independent formulation variables while \% DC (Y1), \% entrapment efficiency $\left(\mathrm{Y}_{2}\right)$, and \% drug released at $12 \mathrm{~h}\left(\mathrm{Y}_{3}\right)$ were considered as dependent or response variables. A statistical model incorporating interactive and polynomial terms were used to evaluate the responses. Design expert (Version 7.0.0) software was used during the generation and evaluation of the statistical experimental design $[17,18]$. The effects of independent variables were modeled using a quadratic mathematical equation generated by a $3^{2}$ factorial design such as:

$$
\mathrm{Y}=\mathrm{b}_{0}+\mathrm{b}_{1} \mathrm{X}_{1}+\mathrm{b}_{2} \mathrm{X}_{2}+\mathrm{b}_{12} \mathrm{X}_{1} \mathrm{X}_{2}+\mathrm{b}_{11} \mathrm{X}_{12}+\mathrm{b}_{22} \mathrm{X}_{22}
$$

Where $\mathrm{Y}$ is the response; $\mathrm{b}_{0}$ is the intercept, and $\mathrm{b}_{1}, \mathrm{~b}_{2}, \mathrm{~b}_{12}$, and $\mathrm{b}_{11} ; \mathrm{b}_{22}$ is regression coefficients. $X_{1}$ and $X_{2}$ are individual effects; $X_{12}$ and $X_{22}$ are quadratic effects; $X_{1}$ and $X_{2}$ are the interaction effect. One-way ANOVA was applied to estimate the significance of models $(\mathrm{p}<0.05)$. Individual response parameters were evaluated using the $F$ test. The surface response plots were analyzed to reveal the effect of independent factors (amount of OBM mucilage and sodium alginate) on the measured responses (\% DC, $\%$ DEE, and \% DR). The details in the design are shown in Tables 1 and 2.

\section{Determination of DC}

Drug loaded gastrospheres (100 mg) were powdered and suspended in $100 \mathrm{ml} 0.1 \mathrm{~N} \mathrm{HCl}$ solution and kept for $24 \mathrm{~h}$. Similar procedure was repeated in phosphate buffer $\mathrm{pH} 6.8$ It was stirred for $5 \mathrm{~min}$ and filtered

Table 1: Selection of levels of independent variables

\begin{tabular}{|c|c|c|}
\hline Coded value & $\begin{array}{l}\text { Sodium } \\
\text { Alginate (mg) } \\
\mathrm{X}_{1}\end{array}$ & $\begin{array}{l}\text { Ocimum basilicum } \\
\text { mucilage (mg) } \\
\mathrm{X}_{2}\end{array}$ \\
\hline $\begin{array}{l}-1 \\
\end{array}$ & 300 & 50 \\
\hline 0 & 400 & 75 \\
\hline 1 & 500 & 100 \\
\hline
\end{tabular}

Table 2: Design layout of $3^{2}$ factorial batches

\begin{tabular}{|c|c|c|c|c|c|}
\hline \multirow[t]{2}{*}{$\begin{array}{l}\text { Batch } \\
\text { code }\end{array}$} & \multicolumn{2}{|c|}{$\begin{array}{l}\text { Coded } \\
\text { value }\end{array}$} & \multicolumn{2}{|c|}{ Actual value } & \multirow[t]{2}{*}{ Drug } \\
\hline & $\mathrm{X}_{1}$ & $\mathbf{X}_{2}$ & SA & $\begin{array}{l}\text { Ocimum basilicum } \\
\text { seed mucilage }\end{array}$ & \\
\hline S1 & -1 & -1 & 300 & 50 & 400 \\
\hline S2 & -1 & 0 & 300 & 75 & 400 \\
\hline S3 & -1 & +1 & 300 & 100 & 400 \\
\hline S4 & 0 & -1 & 400 & 50 & 400 \\
\hline S5 & 0 & 0 & 400 & 75 & 400 \\
\hline S6 & 0 & +1 & 400 & 100 & 400 \\
\hline S7 & +1 & -1 & 500 & 50 & 400 \\
\hline S8 & +1 & 0 & 500 & 75 & 400 \\
\hline S9 & +1 & +1 & 500 & 100 & 400 \\
\hline
\end{tabular}


by Whatman filter paper. CRV content in the filtrate was determined

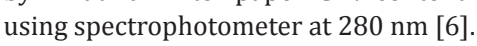

Drug content $=$ Actual drug content $/$ total wt. of gastrosphere taken $\times 100 \%$

\section{Determination of DEE}

Gastrospheres equivalent to $5 \mathrm{mg}$ of CRV was taken and was crushed using pestle and mortar. The crushed powders of drug-containing gastrospheres were placed in $25 \mathrm{ml}$ of $0.1 \mathrm{~N} \mathrm{HCl}$ and kept for $24 \mathrm{~h}$ with occasional shaking at $37 \pm 0.5^{\circ} \mathrm{C}$. After the stipulated time; the mixture was stirred at $500 \mathrm{rpm}$ for 20 min using a magnetic stirrer (Remi Motors, India). The polymer debris formed after disintegration of gastrospheres was removed filtering through Whatman ${ }^{\circledR}$ filter paper (No.40). The DC in the filtrate was determined using an ultraviolet (UV)-Vis spectrophotometer (Lab India) at $280 \mathrm{~nm}$ against appropriate blank. The DEE was calculated using the following formula [6].

$$
\operatorname{DEE}(\%)=\left(\frac{\text { Actual }}{\text { Theoretical }} \text { Drug Content }\right) \times \text { Drug }
$$

\section{Particle size analysis}

The particle size of 100 dried gastrospheres from each batch was measured by optical microscopic method for average particle size using an optical microscope. The ocular micrometer was previously calibrated by stage micrometer. OBM-alginate beads containing CRV were gold-coated using ion-sputter, and at $20 \mathrm{kv}$, their morphology was examined by Scanning electron microscope (JSM 6330 JEOL Japan).

\section{In vitro mucoadhesive test}

The mucoadhesive property of optimized CRV gastrospheres was evaluated by ex vivo wash-off method. Freshly excised pieces of goat intestinal mucosa $(2 \mathrm{~cm} \times 2 \mathrm{~cm})$ (collected from the slaughterhouse) were mounted in the glass slide $(7.5 \mathrm{~cm} \times 2.5 \mathrm{~cm})$ using thread. About 20 gastrospheres were spread onto the wet tissue specimen, and the prepared slide was hung onto a groove of the disintegration test apparatus. The tissue specimen was given a regular up and down movement in a vessel containing $900 \mathrm{ml}$ of $0.1 \mathrm{~N} \mathrm{HCl}$ at $37 \pm 0.5^{\circ} \mathrm{C}$. After regular time intervals, the machine was stopped and the number of gastrospheres still adhering to the tissue was counted [9].

\section{In vitro drug release (DR) study}

The release of CRV from various gastrosphere was tested using a dissolution apparatus USP Type II. The dissolution rate was measured at $37 \pm 0.5^{\circ} \mathrm{C}$ under $50 \mathrm{rpm}$ speed. Accurately weighed quantities of gastrospheres containing $\mathrm{CRV}$ equivalent to $50 \mathrm{mg}$ were added to $900 \mathrm{ml}$ of $0.1 \mathrm{~N} \mathrm{HCl} .5 \mathrm{ml}$ sample was collected at regular time intervals, and the same amount of a fresh dissolution medium was replaced into the dissolution vessel to maintain the sink condition throughout the experiment. The collected aliquots were filtered and suitably diluted to determine the absorbance using a UV-Vis spectrophotometer (Lab India) at $280 \mathrm{~nm}$ against an appropriate blank.

\section{FTIR spectroscopy}

Samples were reduced to powder and analyzed as $\mathrm{KBr}$ pellets using a FTIR spectroscopy. The pellet was placed in the sample holder spectral scanning was taken in the wavelength region between 4000 and $400 \mathrm{~cm}^{-1}$ with a scan speed of $\mathrm{km} / \mathrm{s}$.

\section{Powder X-ray diffraction (PXRD)}

PXRD patterns were recorded using BRUCKER D2 PHASER A26-X1 ABOB2A, fitted with a copper target, a voltage of $40 \mathrm{kV}$, and a current of $30 \mathrm{~mA}$. The scanning rate was $1^{\circ} / \mathrm{min}$ over a $2 \theta$ range of $1-50^{\circ}$. PXRD patterns were traced for CRV, physical mixture, and formulation. The samples were slightly ground and packed into the aluminum sample container.

\section{Differential scanning calorimetric (DSC)}

DSC analysis of the samples was carried out on a PerkinElmer DSC7, USA. Samples (6.5-10 mg) were heated under nitrogen atmosphere on an aluminum pan at a heating rate of $10{ }^{\circ} \mathrm{C} / \mathrm{min}$ over the temperature range of 5 and $300^{\circ} \mathrm{C}$. DSC analysis was carried out under nitrogen gas flow of $20 \mathrm{lb} / \mathrm{in}^{2}$.

\section{RESULTS AND DISCUSSION}

Isolation of $O$. basilicum mucilage and preparation of OBM-alginate gastrospheres containing CRV

OBM was isolated from raw seeds of 0 . basilicum, and the average yield of dried OBM was found $20.16 \% \mathrm{w} / \mathrm{w}$. The OBM-alginate gastrospheres containing CRV was prepared through ionotropically gelation using $\mathrm{CaCl}_{2}$ as cross linker. When dispersion mixture of sodium alginate, OBM and CRV were dropped into the solutions containing $\mathrm{Ca}^{2+}$ ions, ionotropically gelled OBM-alginate gastrospheres containing CRV were formed instantaneously due to an electrostatic ionic interaction between negatively charged $\mathrm{COO}^{-}$groups of sodium alginate and positively charged $\mathrm{Ca}^{2+}$ ions. Actually, $\mathrm{Ca}^{2+}$ ions are accommodated in the interstices of two polycarbonate chains having a close ion-pair interaction with $\mathrm{COO}^{-}$anions of the sodium alginate and sufficient coordination by other electronegative oxygen atoms [19].

\section{Optimization studies}

The influences of factors on investigating responses were elucidated by response surface methodology (Table 3).

Response surface methodology is a widely used approach for the development and optimization of drug delivery formulations, which has been utilized by the formulators to investigate the combined effect of investigating factors on the desired responses. The three-dimensional response surface graphs are very useful in learning about the main effects and interaction effects of the independent variables. The threedimensional response surface plots (Figs. 1 and 2) were presented to estimate the effects of the independent variables (factors) on each response investigated. The values of investigated responses measured for all trial formulations were fitted in the $3^{2}$ factorial designs to get model equations for responses analyzed in this investigation. These models were evaluated statistically by applying one-way ANOVA $(p<0.05)$. The fitted model for DC is a quadratic model and expressed as the final equation in terms of actual factors as follows:

a. $\quad$ Drug content $=+11.91500+0.043183 \mathrm{SA}+0.0111330 \mathrm{BM}$

$\left[\mathrm{R}^{2}=0.8450\right.$; adjusted $\mathrm{R}^{2}=0.7933$; predicted $\mathrm{R}^{2}=0.6353 ; \mathrm{F}=16.35$; $\mathrm{p}<0.05]$

From the RSM plot for DC (Fig. 1), it is observed that the change in concentration of sodium alginate and $O$. basilicum mucilage affects DC. It is observed that with increase in concentration of sodium alginate DC increases; however, increase in concentration of $O$. basilicum mucilage decreased DC. From the statistical second-order complete model equation, it can be concluded that among the polymers used

Table 3: Result of ANOVA for factorial design batches

\begin{tabular}{|c|c|c|c|c|c|}
\hline Source & $\begin{array}{l}\text { Sum of } \\
\text { square }\end{array}$ & Df & $\begin{array}{l}\text { Mean } \\
\text { square }\end{array}$ & F value & $p>F$ \\
\hline \multicolumn{6}{|c|}{ Drug content } \\
\hline Model & 112.35 & 2 & 56.18 & 16.35 & $0.0037(\mathrm{~S})$ \\
\hline $\mathrm{X}_{1}$ & 111.89 & 1 & 111.89 & 32.57 & $0.0013(S)$ \\
\hline $\mathrm{X}_{2}^{1}$ & 0.46 & 1 & 0.46 & 0.14 & $0.7256(\mathrm{NS})$ \\
\hline \multicolumn{6}{|c|}{ Drug entrapment efficiency } \\
\hline Model & 108.44 & 3 & 36.15 & 375.40 & $<0.0001(\mathrm{~S})$ \\
\hline $\mathrm{X}_{1}$ & 104.08 & 1 & 104.08 & 1080.96 & $<0.0001$ (S) \\
\hline $\mathrm{x}_{2}^{1}$ & 3.38 & 1 & 3.38 & 35.05 & $0.0020(\mathrm{~S})$ \\
\hline $\mathrm{X}_{1}^{2} \mathrm{X}_{2}$ & 0.98 & 1 & 0.98 & 10.18 & $0.0243(\mathrm{~S})$ \\
\hline \multicolumn{6}{|c|}{ Drug release } \\
\hline Model & 133.75 & 2 & 66.87 & 7.10 & $0.0262(\mathrm{~S})$ \\
\hline$x_{1}$ & 12.88 & 1 & 12.88 & 1.37 & $0.2867(\mathrm{NS})$ \\
\hline $\mathrm{X}_{2}^{1}$ & 120.87 & 1 & 120.87 & 12.83 & $0.0116(\mathrm{~S})$ \\
\hline
\end{tabular}

$\mathrm{S}$ and NS indicate significant and nonsignificant, respectively. d.f. indicate degree of freedom 
O. basilicum mucilage had a more profound effect on DC as compared to sodium alginate.

b. Entrapment efficiency $=+15.81111+0.056500 \mathrm{SA}+0.10920$ OBM-1.98000E- $004 \times$ SA $\times 0 B M$

$\left[\mathrm{R}^{2}=0.9956\right.$; adjusted $\mathrm{R}^{2}=0.9929$; predicted $\mathrm{R}^{2}=0.9905 ; \mathrm{F}=375.40$; $\mathrm{p}<0.05]$

From the RSM plot for DEE (Fig. 2), it is observed that the change in concentration of sodium alginate and $O$. basilicum mucilage affects DEE. It was observed that with increase in concentration of sodium alginate DEE increases; however, increase in concentration of 0 . basilicum mucilage decreased DEE. From the statistical second-order complete model equation, it can be concluded that among the polymers used $O$. basilicum mucilage had a more profound effect on DEE as compared to sodium alginate.

c. Drug release $=+55.29722+0.014650 \mathrm{SA}+0.179530 \mathrm{BM}$.

$\left[\mathrm{R}^{2}=0.7029\right.$; adjusted $\mathrm{R}^{2}=0.6039$; predicted $\mathrm{R}^{2}=0.3418 ; \mathrm{F}=7.10$; $\mathrm{p}<0.05]$

From the RSM plot for DR (Fig. 3), it is observed that the change in concentration of sodium alginate and $O$. basilicum mucilage affects DR. It was observed that increase in concentration of sodium alginate increased the DR up to certain extent further increase in concentration of sodium alginate retarded the DR values. However, a decrease in DR

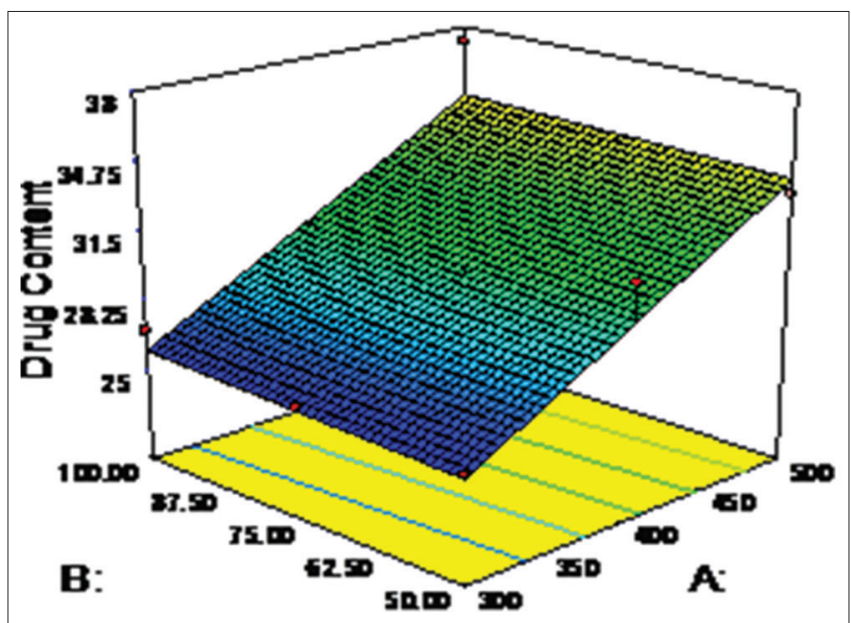

Fig. 1: Response surface plot of drug content (A: Sodium alginate, B: Ocimum basilicum mucilage)

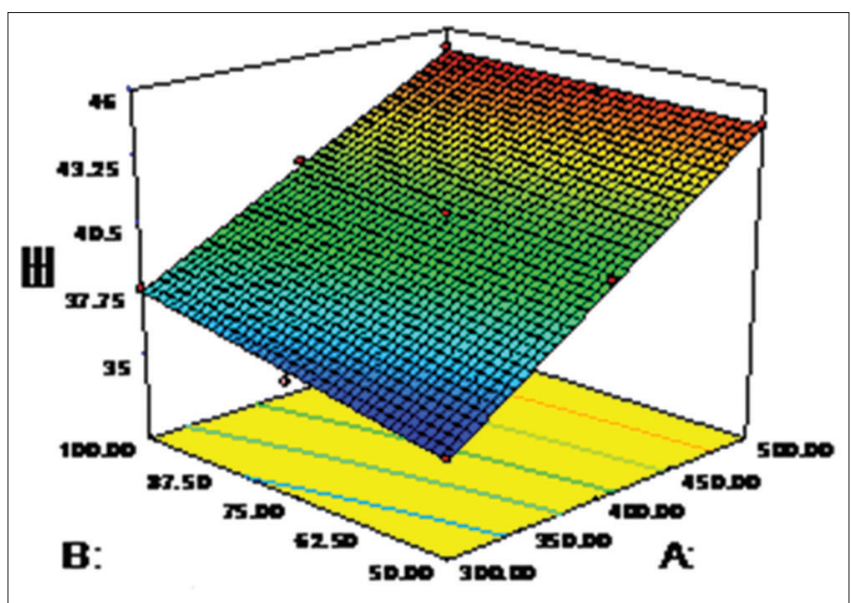

Fig. 2: Response surface plot of daily energy expenditure (A: Sodium alginate, B: Ocimum basilicum mucilage) values with the increasing 0 . basilicum mucilage $\left(\mathrm{X}_{2}\right)$ is indicated by the three-dimensional response surface graph relating DR (Fig. 3). Surface response plot indicates that sodium alginate concentration at optimum level $400 \mathrm{mg}$ yielded microspheres with highest DR with 0 . basilicum mucilage concentration at $75 \mathrm{mg}$. Hence, the optimized batch was found to be $\mathrm{S} 4$ with optimum level of sodium alginate and 0 . basilicum mucilage.

\section{Results of DC and entrapment efficiency}

The formulated CRV mucoadhesive gastrospheres were characterized for different parameters by varying the solvent $\mathrm{pH}$. The results of DC and DEE were obtained in different solvent $\mathrm{pH}$, namely, $0.1 \mathrm{~N} \mathrm{HCl}$ and phosphate buffer $\mathrm{pH} 6.8$ for determining the effect of solvent $\mathrm{pH}$ on the above parameters.

$D C$

In these methods, drug is uniformly distributed in the polymer solution, so drug can be loaded easily in the polymer. DC analysis for the nine batches based on sodium alginate and $O$. basilicum mucilage concentration in both medium $(0.1 \mathrm{~N} \mathrm{HCl}$ and phosphate buffer $\mathrm{pH} 6.8)$ is shown in Table 4, which concludes that DC values were ranging from $25.58 \%$ to $37.26 \%$ in $0.1 \mathrm{~N} \mathrm{HCl}$ and $46.05 \%$ to $57.45 \%$ DC values for phosphate buffer $\mathrm{pH}$ 6.8. It was found that DC increases with an increase in polymer concentration.

DEE

The entrapment efficiency determines the percentage of entrapped drug with respect to the total drug introduced into a polymer solution. Effect of $O$. basilicum mucilage content on entrapment efficiency was studied.

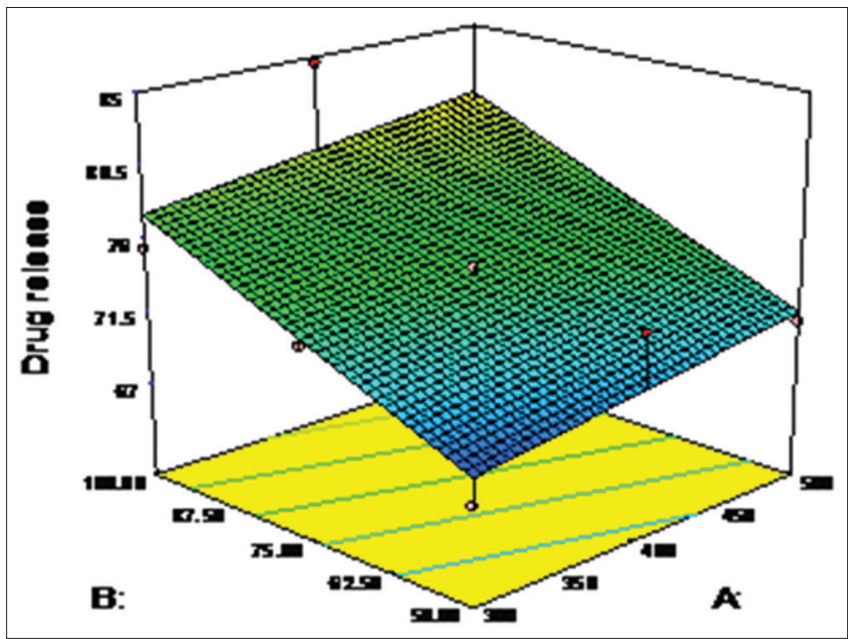

Fig. 3: Response surface plot of drug release (A: Sodium alginate, B: Ocimum basilicum mucilage)

Table 4: Results of drug content of CRV gastrospheres

\begin{tabular}{lll}
\hline Formulation & $\begin{array}{l}\text { Drug content \% } \\
\text { (0.1N HCl) }\end{array}$ & $\begin{array}{l}\text { Drug content (\%) } \\
\text { (phosphate buffer } \mathbf{~ p H ~ 6 . 8 ) ~}\end{array}$ \\
\hline S1 & $25.58 \pm 0.164$ & $48.10 \pm 0.327$ \\
S2 & $25.82 \pm 0.124$ & $46.05 \pm 0.396$ \\
S3 & $26.91 \pm 0.063$ & $47.64 \pm 0.196$ \\
S4 & $31.48 \pm 0.185$ & $57.45 \pm 0.184$ \\
S5 & $28.26 \pm 0.218$ & $55.50 \pm 0.225$ \\
S6 & $27.94 \pm 0.100$ & $55.35 \pm 0.122$ \\
S7 & $33.38 \pm 0.253$ & $53.70 \pm 0.073$ \\
S8 & $33.58 \pm 0.220$ & $53.01 \pm 0.012$ \\
S9 & $37.26 \pm 0.214$ & $53.62 \pm 0.367$ \\
\hline SD: Standard deviation for $=3$. CRV: Carvedilol
\end{tabular}

SD: Standard deviation for $\mathrm{n}=3$. CRV: Carvedilol 
Entrapment efficiency in $0.1 \mathrm{~N} \mathrm{HCl}$ and phosphate buffer $\mathrm{pH} 6.8$ was found to be in the range from 35.32 to $45.13 \%$ and 56.39 to $70.49 \%$, respectively (Table 5); it is evident that with increase in 0 . basilicum mucilage concentration entrapment efficiency also increased. This may be due to increase in viscosity with increased $O$. basilicum mucilage concentration.

\section{Particle size analysis}

All the formulations were spherical in particle shape with a smooth surface. The mean particle size of gastrospheres ranged from 774 to $882 \mu \mathrm{m}$, (Table 6) which indicate the large particle size distribution. It was also noted that increase in drug to mucilage ratio increases the particle size due to increased viscosity of feed solution which influences the interaction between disperse phase and dispersion medium that affects the size distribution of particle.

\section{In vitro mucoadhesive test}

The in vitro wash off test using goat intestinal mucosa for assessing mucoadhesive of gastrosphere containing CRV was performed at both gastric $\mathrm{pH}(0.1 \mathrm{~N} \mathrm{HCl}, \mathrm{pH} 1.2)$ and intestinal $\mathrm{pH}$ (phosphate buffer, $\mathrm{pH} 6.8$ ) for $8 \mathrm{~h}$. In $0.1 \mathrm{~N} \mathrm{HCl}$, the percentage of gastrosphere adhering to the goat intestinal mucosal tissue varied from $10 \%$ to $65 \%$ over $8 \mathrm{~h}$, whereas this was varied from $40 \%$ to $60 \%$ in phosphate buffer $\mathrm{pH} 6.8$ (Tables 7 and 8).

The mucoadhesion test results reflect a decrease in mucoadhesion of CRV gastrospheres in both gastric $\mathrm{pH}(0.1 \mathrm{~N} \mathrm{HCl}, \mathrm{pH} 1.2)$ and intestinal $\mathrm{pH}$ (phosphate buffer, $\mathrm{pH}$ 6.8) the reason may be due to the reason that at lower concentration the $O$. basilicum mucilage structure is more loose and the polymer chain have more space to extend within the mucus, as the number of $O$. basilicum mucilage chains penetrating in mucus is increased a strong bond, either chemical, mechanical or the both is formed between the mucus and the 0 . basilicum mucilage [20]. Among all nine batches $\mathrm{S} 4$ batch gave highest mucoadhesive property.

\section{In vitro $\mathrm{DR}$}

Gastrospheres were subjected to in vitro release using basket type dissolution apparatus in $900 \mathrm{ml}$ of $0.1 \mathrm{~N} \mathrm{HCl}$ medium. The results of the in vitro DR studies were given in Table 9.

Table 5: Results of entrapment efficiency of carvedilol gastrospheres

\begin{tabular}{lll}
\hline Formulation & $\begin{array}{l}\text { E.E } \\
(\mathbf{0 . 1 N} \mathbf{H C l})\end{array}$ & $\begin{array}{l}\text { E.E } \\
\text { (phosphate buffer } \mathbf{p H ~ 6 . 8 )}\end{array}$ \\
\hline S1 & $35.32 \pm 0.231$ & $56.39 \pm 0.424$ \\
S2 & $36.03 \pm 0.348$ & $59.05 \pm 0.425$ \\
S3 & $37.85 \pm 0.195$ & $60.66 \pm 0.232$ \\
S4 & $40.10 \pm 0.46$ & $70.49 \pm 0.214$ \\
S5 & $40.94 \pm 0.28$ & $66.22 \pm 0.472$ \\
S6 & $41.52 \pm 0.37$ & $65.51 \pm 0.397$ \\
S7 & $44.58 \pm 0.30$ & $65.48 \pm 0.506$ \\
S8 & $44.48 \pm 0.46$ & $60.33 \pm 0.235$ \\
S9 & $45.13 \pm 0.517$ & $64.08 \pm 0.422$ \\
\hline
\end{tabular}

SD: Standard deviation for $\mathrm{n}=3$

Table 6: Carvedilol loaded mucoadhesive gastrospheres particle size analysis

\begin{tabular}{ll}
\hline Formulation & Particle size \\
\hline S1 & $830 \pm 5.77$ \\
S2 & $774 \pm 5.93$ \\
S3 & $798 \pm 6.43$ \\
S4 & $810 \pm 4.37$ \\
S5 & $838 \pm 7.51$ \\
S6 & $854 \pm 11.6$ \\
S7 & $862 \pm 8.33$ \\
S8 & $874 \pm 5.93$ \\
S9 & $882 \pm 2.96$ \\
\hline
\end{tabular}

The release seems to be somewhat sustained with increase in the amount of $O$. basilicum mucilage. The release rate was found to be decreased in accordance with the increase in the ratio of $O$. basilicum mucilage used. CRV release from the gastrospheres was studied in gastric buffer $0.1 \mathrm{~N} \mathrm{HCl}$ for $12 \mathrm{~h}$. In case of gastrosphere containing higher 0 . basilicum mucilage contents, the more hydrophilic property of the mucilage could probably bind better with water to form viscous gel structure, which might blockade the pores on the surface of gastrosphere and could delay the DR from these formulated gastrospheres [20]. The another reasonable explanation of the delayed DR can be attributed to increasing coating efficiency of the drug particles with the increasing 0 . basilicum mucilage content employed in the formulation. Among all the fabricated formulation, S4 was chosen as an ideal formulation showing an extended DR over a period of $12 \mathrm{~h}(84.58 \%)$ with acceptable mucoadhesive property.

\section{Analysis of DR kinetics and mechanism}

The in vitro DR data from various mucoadhesive gastrosphere containing CRV were evaluated kinetically using various mathematical models such as zero-order, first-order, and Higuchi, and KorsmeyerPeppas model $[20,21]$. The results of the curve fitting into these abovementioned mathematical models are given in Table 10.

When respective correlation coefficients of this gastrosphere were compared, the CRV release from this gastrosphere was found to follow zero-order model $\left(R^{2}=0.969-0.998\right)$ over a period of $12 \mathrm{~h}$. The best fit of zero-order model indicated that the drug released from this gastrosphere followed sustained release pattern. The values of release exponent (n) determined from in vitro DR data of various CRV gastrosphere S3, S4, S6, S7, S8, and S9 follow the anomalous non-Fickian DR (0.61-0.822), i.e., the rate of solvent penetration and DR is in the same range, and S1, S2, and S5 indicating the DR from this gastrosphere followed the Case-II transport mechanism controlled by swelling and relaxation of polymeric blend in gastrosphere matrix. This could be attributed due to $O$. basilicum mucilage polymer dissolution and enlargement or relaxation of polymeric chain $[14,22]$.

Table 7: Mucoadhesive test in 0.1N HCl

\begin{tabular}{lllllllll}
\hline Formulation & \multicolumn{7}{c}{ \% mucoadhesion test (h) } \\
\cline { 2 - 9 } & $\mathbf{1}$ & $\mathbf{2}$ & $\mathbf{3}$ & $\mathbf{4}$ & $\mathbf{5}$ & $\mathbf{6}$ & $\mathbf{7}$ & $\mathbf{8}$ \\
\hline S1 & 90 & 90 & 85 & 75 & 75 & 65 & 65 & 60 \\
S2 & 70 & 60 & 50 & 40 & 35 & 25 & 15 & 10 \\
S3 & 95 & 90 & 90 & 80 & 70 & 70 & 60 & 60 \\
S4 & 95 & 95 & 90 & 90 & 70 & 70 & 65 & 65 \\
S5 & 100 & 75 & 75 & 65 & 60 & 60 & 50 & 40 \\
S6 & 95 & 80 & 80 & 75 & 70 & 70 & 65 & 60 \\
S7 & 95 & 90 & 85 & 80 & 70 & 70 & 60 & 60 \\
S8 & 90 & 80 & 75 & 70 & 60 & 60 & 50 & 45 \\
S9 & 100 & 90 & 80 & 75 & 70 & 70 & 60 & 60 \\
\hline
\end{tabular}

Table 8: Mucoadhesion test in phosphate buffer pH 6.8

\begin{tabular}{lllllllll}
\hline \multirow{2}{*}{ Formulation } & \multicolumn{1}{c}{ \% Mcoadhesion test (h) } \\
\cline { 2 - 9 } & $\mathbf{1}$ & $\mathbf{2}$ & $\mathbf{3}$ & $\mathbf{4}$ & $\mathbf{5}$ & $\mathbf{6}$ & $\mathbf{7}$ & $\mathbf{8}$ \\
\hline S1 & 90 & 75 & 50 & 25 & 10 & - & - & - \\
S2 & 90 & 65 & 55 & 30 & 20 & 10 & - & - \\
S3 & 100 & 75 & 70 & 70 & 60 & 60 & 50 & 50 \\
S4 & 100 & 95 & 80 & 75 & 65 & 65 & 60 & 60 \\
S5 & 95 & 95 & 90 & 80 & 70 & 60 & 50 & 50 \\
S6 & 100 & 100 & 95 & 90 & 75 & 65 & 55 & 50 \\
S7 & 90 & 80 & 75 & 75 & 65 & 60 & 60 & 50 \\
S8 & 95 & 85 & 80 & 80 & 75 & 70 & 60 & 55 \\
S9 & 100 & 95 & 85 & 80 & 80 & 65 & 50 & 40 \\
\hline
\end{tabular}


Table 9: Summary of results of dependent variables

\begin{tabular}{|c|c|c|c|c|c|}
\hline \multirow[t]{2}{*}{ Formulation } & \multicolumn{2}{|c|}{$\begin{array}{l}\text { Variable levels in coded } \\
\text { form }\end{array}$} & \multirow[t]{2}{*}{$\begin{array}{l}\text { Drug content } \\
(0.1 \mathrm{~N} \mathrm{HCl})(\%)\end{array}$} & \multirow[t]{2}{*}{$\begin{array}{l}\text { Entrapment efficiency } \\
(0.1 \mathrm{~N} \mathrm{HCl})(\%)\end{array}$} & \multirow[t]{2}{*}{$\begin{array}{l}\text { Drug release } \\
(0.1 \mathrm{~N} \mathrm{HCl})(\%)\end{array}$} \\
\hline & $\mathrm{X}_{1}$ & $\mathbf{X}_{2}$ & & & \\
\hline S1 & -1 & -1 & 25.58 & 35.32 & 67.00 \\
\hline S2 & -1 & 0 & 25.82 & 36.03 & 72.67 \\
\hline S3 & -1 & +1 & 26.91 & 37.85 & 75.50 \\
\hline S4 & 0 & -1 & 31.48 & 40.10 & 84.58 \\
\hline S5 & 0 & 0 & 28.26 & 40.94 & 74.37 \\
\hline S6 & 0 & +1 & 27.94 & 41.52 & 73.52 \\
\hline S7 & +1 & -1 & 33.38 & 44.58 & 74.65 \\
\hline S8 & +1 & 0 & 33.58 & 44.48 & 70.97 \\
\hline S9 & +1 & +1 & 37.26 & 45.13 & 78.34 \\
\hline
\end{tabular}

Table 10: Release kinetics data

\begin{tabular}{|c|c|c|c|c|c|c|}
\hline \multicolumn{7}{|c|}{ Release kinetics } \\
\hline Formulation & Zero-order $\mathbf{R}^{2}$ & First-order $\mathbf{R}^{2}$ & Higuchi $\mathbf{R}^{2}$ & Hixson-Crowell $\mathbf{R}^{2}$ & Korsmeyer-Peppas $\mathbf{R}^{2}$ & n (slope) \\
\hline S1 & 0.991 & 0.966 & 0.942 & 0.978 & 0.993 & 1.004 \\
\hline S2 & 0.992 & 0.962 & 0.953 & 0.978 & 0.969 & 1.061 \\
\hline S3 & 0.993 & 0.978 & 0.972 & 0.989 & 0.983 & 0.702 \\
\hline S4 & 0.994 & 0.938 & 0.959 & 0.97 & 0.976 & 0.756 \\
\hline S5 & 0.996 & 0.953 & 0.96 & 0.975 & 0.987 & 0.873 \\
\hline S6 & 0.998 & 0.944 & 0.943 & 0.965 & 0.966 & 0.677 \\
\hline S7 & 0.969 & 0.878 & 0.896 & 0.916 & 0.976 & 0.822 \\
\hline S8 & 0.987 & 0.94 & 0.928 & 0.961 & 0.947 & 0.61 \\
\hline S9 & 0.986 & 0.918 & 0.925 & 0.948 & 0.947 & 0.701 \\
\hline Best fit model & Zero-order & & & & & \\
\hline
\end{tabular}

\section{FTIR spectroscopy analysis}

IR spectra of CRV and its combination with excipients are shown in Fig. 4. An IR spectrum of pure CRV showed characteristic peaks at $3352.05 \mathrm{~cm}^{-1}(\mathrm{O}-\mathrm{H}$ and $\mathrm{N}-\mathrm{H}$ stretching vibration peaks merged together), $2938.40 \mathrm{~cm}^{-1}$ (C-H stretching vibrations), $1596.88 \mathrm{~cm}^{-1}(\mathrm{~N}-\mathrm{H}$ bending vibrations), and $1241.16 \mathrm{~cm}^{-1}$ (O-H bending and $\mathrm{C}-0$ stretching vibrations). These peaks can be considered as characteristic peaks of CRV and were not affected and prominently observed in IR spectra of CRV along with excipients as shown in Fig. 4 indicated no interaction between CRV and excipients.

The IR spectrum of the formulation showed that there was no significant evidence for interaction between drug and the 0 . basilicum mucilage. Peaks of both drug and formulation were observed and interpreted. Hence, this clearly suggests that drug, polymers, and excipients used for the current study have not found any interaction.

\section{XRD analysis}

Substances in solid state can present crystalline or amorphous characteristics and in some cases both. A crystal has an ordered arrangement of molecules and atoms, maintained in contact through non-covalent interactions. On the other hand, amorphous solids are characterized by a random state. These characteristics are important in the absorption process. Amorphous solids are, in general, more soluble than the crystalline form, due to free energies involved in the dissolution process. Solids in amorphous state have randomly arranged molecules, and thus low energy is required to separate them and, consequently, their dissolution is faster than when in the crystalline form. The CRV has crystalline characteristics which are represented by peaks in X-ray diffractograms (Fig. 5), and the most evident peaks appear at $2 \theta=12.67$, $13.18,19.60$, and 22.14. These peaks were not observed in the CRV loaded gastrospheres. This indicates that drug particles are dispersed at molecular level in the polymer matrices since no indication about the crystalline nature of the drugs was observed in the drug-loaded gastrospheres [23-26].

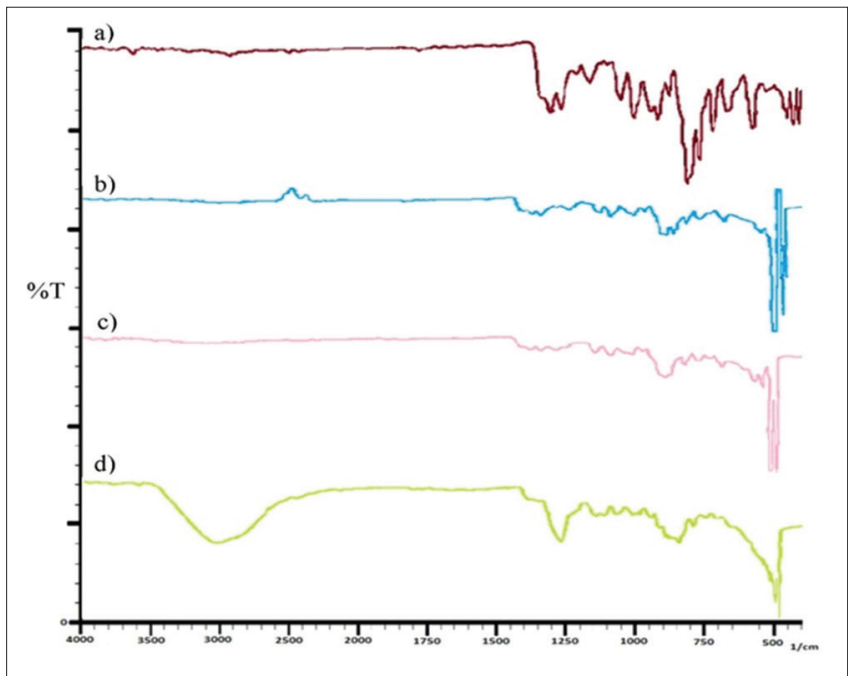

Fig. 4: Infrared spectra of a) carvedilol (CRV) b) CRV + Ocimum basilicum mucilage c) CRV + O. basilicum mucilage + Sod. alginate d) formulation $\mathrm{S} 4$

DSC analysis

DSC is a fast and reliable method for understanding the polymorphic transition when screening drugs and excipients for compatibility, obtaining information about possible interactions. The results of DSC studies are shown in Fig. 6. DSC thermogram showed an endothermic peak of $\mathrm{CRV}$ at $87^{\circ} \mathrm{C}$, which corresponds to its melting point. The presence of detectable peaks of CRV in a physical mixture is an indication of uniform mixing of excipients. The absence of peaks of CRV loaded gastrospheres in formulation S4 clearly indicates that CRV was dispersed completely in the formulation, thus modifying the gastrospheres to an amorphous, disordered crystalline phase [25]. 


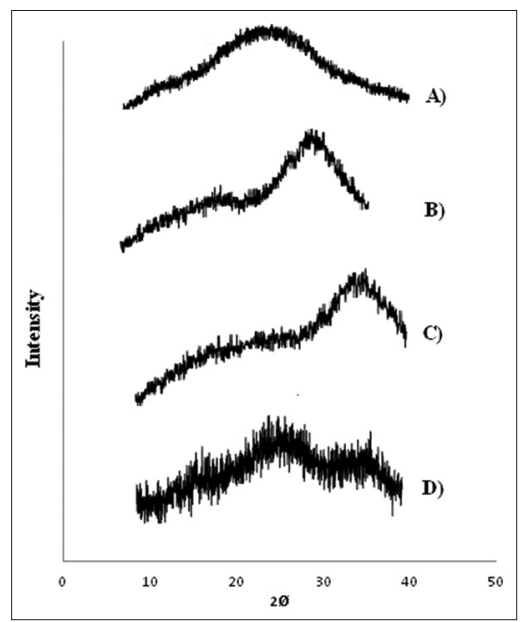

Fig. 5: A) Carvedilol (CRV) B) CRV + Ocimum basilicum mucilage C) $\mathrm{CRV}+$ O. basilicum mucilage + NA. alginate D) formulation S4

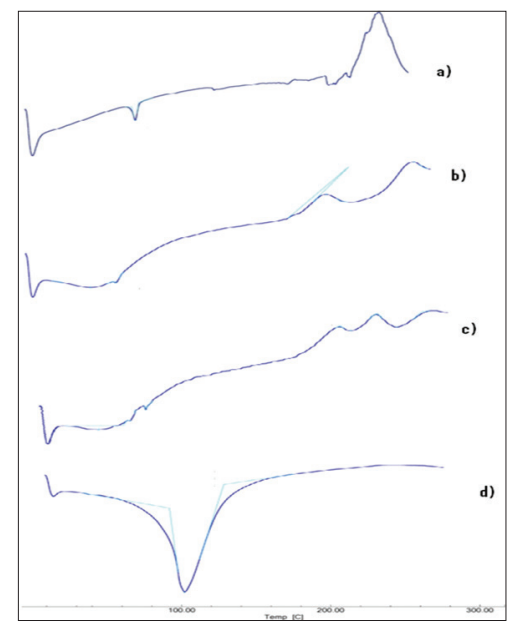

Fig. 6: a) Carvedilol (CRV) b) CRV + Ocimum basilicum mucilage c) CRV + O. basilicum mucilage + NA. alginate d) formulation S4

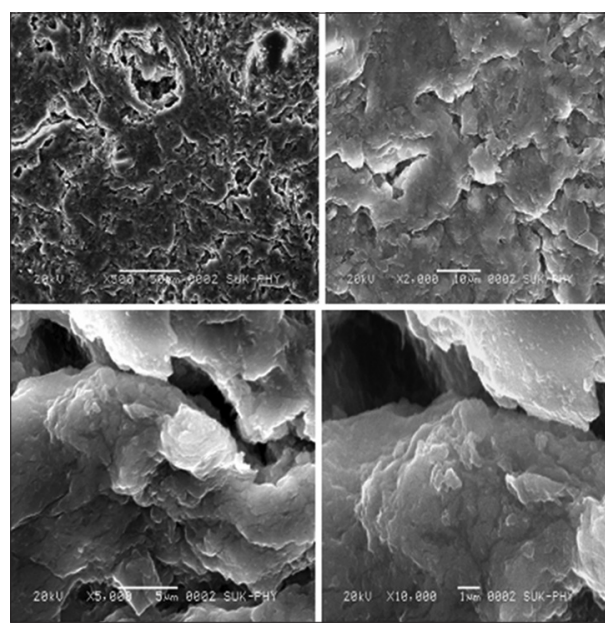

Fig. 7: Scanning electron photograph of drug-loaded gastrosphere (magnification $\times 500, \times 2000, \times 5000, \times 10,000$ )

\section{Scanning electron microscopy (SEM)}

The morphological analysis of the mucoadhesive gastrospheres was studied by SEM. SEM photomicrographs of optimize formulation S4 gastrospheres were rough spherical and showed few pores on surface, due to uniform distribution of the drug in formulation, as shown in Fig. 7.
Particulate matter of the drug and 0 . basilicum mucilage was seen on the surface of the gastrospheres, indicating uniform distribution of the drug in the polymeric network [23]. The SEM photographs indicated that the gastrospheres were completely covered with polymer the rough texture which may be due to removal of water from gastrospheres during drying. Thus the rate of removal of water from gastrospheres exerts an influence on the morphology of final product [23-28].

\section{CONCLUSION}

The present study concludes that mucoadhesive gastrosphere of CRV can be prepared using the ionotropic gelation method. $3^{2}$ full factorial designs are suitable to study the effect of process variables on formulation characteristics by applying statistical analysis. From the study, we successfully developed microparticulate DDS of CRV using as mucilage/mucoadhesive polymer isolated from 0 . basilicum seeds and rate retardant sodium alginate polymer.

\section{AUTHORS' CONTRIBUTIONS}

The first author carried out literature review, critical analysis, idea generation, and experimental work. The second author supervised the methodology implemented and helped in drafting of manuscript.

\section{CONFLICTS OF INTEREST}

There are no conflicts of interest among the authors.

\section{REFERENCES}

1. Patwekar S, Baramade MK. Controlled release approach to novel multiparticulate drug delivery system. Int $\mathrm{J}$ Pharm Pharm Sci 2012;4:757-63.

2. Wong CY, Al-Salami H, Dass CR. Microparticles, microcapsules and microspheres: A review of recent developments and prospects for oral delivery of insulin. Int J Pharm 2018;537:223-44.

3. Patel MM. Formulation and development of di-dependent microparticulate system for colon-specific drug delivery. Drug Deliv Transl Res 2017:7:312-24

4. Oliveira MB, da Silva JB, Montanha MC, Kimura E, Diniz A, Bruschi ML, et al. Design and characterization of mucoadhesive gelatin-ethylcellulose microparticles for the delivery of curcumin to the bladder. Curr Drug Deliv 2018;15:1112-22.

5. Di Prima G, Conigliaro A, De Caro V. Mucoadhesive polymeric films to enhance barbaloin penetration into buccal mucosa: A novel approach to chemoprevention. AAPS PharmSciTech 2019;20:18.

6. Sakhare SS, Yadav AV, Jadhav PD. Design, development and characterization of mucoadhesive gastro spheres of carvedilol. Int $\mathrm{J}$ Appl Pharm 2016;8:37-42.

7. Leichner C, Jelkmann M, Bernkop-Schnürch A. Thiolated polymers: Bioinspired polymers utilizing one of the most important bridging structures in nature. Adv Drug Deliv Rev 2019; S0169409X(19)30049-3.

8. Patil PS. Natural excipients: Uses of pharmaceutical formulations. Int J PharmTech Res 2014;6:21-8.

9. Kamble MS, Mendake SD, Chaudhari PD, Aute PP. Evaluation of binding property of Ocimum tenuiflorum Linn. Seed mucilage isolated by defatting method. J Biomed Pharm Res 2012;3:22-7.

10. Jania GK, Shah DP, Prajapatia VD, Jain VC. Gums and mucilages: Versatile excipients for pharmaceutical formulations. Asian J Pharm Sci 2009; 4:308-22

11. Malviya R, Srivastava P, Kulkarni GT. Applications of mucilages in drug delivery-a review. Adv Biol Res 2011;5:1-7.

12. Osano JP, Hosseini-Parvar SH, Matia-Merino L, Golding M. Emulsifying properties of a novel polysaccharide extracted from basil seed (Ocimum basilicum L.): Effect of polysaccharide and protein content. Food Hydrocoll 2014;37:40-8.

13. Khazaei N, Esmaiili M, Djomeh ZE, Ghasemlou M, Jouki M. Characterization of new biodegradable edible film made from basil seed (Ocimum basilicum L.) gum. Carbohydr Polym 2014;102:199-206.

14. Bal T, Sengupta S, Padala S, Murthy N. Formulation and evaluation of carvedilol microcapsules using eudragit NE30D and sodium aliginate. Braz J Pharm Sci 2013;49:879-900

15. Yelugam M, Koteshwara KB, Reddy MS. Gastroretentive floating microspheres of carvedilol: Formulation, characterization and in vitro evaluation. Int J Pharm Pharm Sci 2013;5:686-90. 
16. Sayyad FJ, Sakhare SS. Isolation, characterization and evaluation of Ocimum basilicum seed mucilage for tableting performance. Indian J Pharm Sci 2018;80:282-90.

17. Prajapati VD, Jani GK, Moradiya NG, Randeria NP, Maheriya PM, Nagar BJ, et al. Locust bean gum in the development of sustained release mucoadhesive macromolecules of aceclofenac. Carbohydr Polym 2014;113:138-48.

18. Joshi P, Patel MR, Patel KR. Design and development of carvedilol phosphate floating microsphere. Int $\mathrm{J}$ Pharmamedix India 2013;1:557-71.

19. Singh B, Sharma V, Chauhan D. Gastroretentive floating sterculiaalginate beads for use in antiulcer drug delivery. Chem Eng Res Des 2010;88:997-1012

20. Nayaka AK, Pal D, Das S. Calcium pectinate-fenugreek seed mucilage mucoadhesive beads for controlled delivery of metformin $\mathrm{HCl}$. Carbohydr Polym 2013;96:349-57.

21. Manohar SD, Dhake AS, Mallikarjuna SC. A research article on solubility and dissolution enhancement of carvedilol by solid dispersion technique using gelucire 50/13. Int J Pharm Sci Rev Res 2014;29:161-5.

22. Brahmankar DM, Jaiswal SB. Biopharmaceutics and Pharmacokinetics a Treaties. New Delhi: Vallabh Prakashan; 2013.
23. Wittaya-areekul S, Kruenate J, Prahsarn C. Preparation and in vitro evaluation of mucoadhesive properties of alginate/chitosan microparticles containing prednisolone. Int J Pharm 2006;312:113-8.

24. Jaswir I, Noviendri D, Taher M, Mohamed F, Octavianti F, Lestari W, et al. Optimization and formulation of fucoxanthin-loaded microsphere (F-LM) using response surface methodology (RSM) and analysis of its fucoxanthin release profile. Molecules 2019;24:E947.

25. Patil S, Babbar A, Mathur R, Mishra A, Sawant K. Mucoadhesive chitosan microspheres of carvedilol for nasal administration. J Drug Target 2010;18:321-31

26. Riekes MK, Barboza FM, Veccia DD, Bohatch M Jr., Farago VV, Farnandes D, et al. Evaluation of oral carvedilol microparticles prepared by simple emulsion technique using poly (3-hydroxybutyrateco-3-hydroxyvalerate) and polycaprolactone as polymers. Mater Sci Eng C 2011;31:962-8.

27. Gada S, Anandkumar Y, Settee M. Drumstick mucilage microspheres for controlled release of lamivudine: Design, optimization and in vitro evaluation. Int J Pharm Pharm Sci 2019;11:60-8.

28. Chakra BP, Saumen K, Das B, Debnath S, Chatterjee TK. Controlled release microsphere formulation of an anti-diabetic drug and characterization of the microsphere. Int J Pharm Pharm Sci 2018;10:30-8. 